\title{
The Protection and Activation of Shanxi Jinzhong Historical and Cultural City from the Perspective of Humanity
}

\author{
Gao Jie*, Zhai Hongyu \\ Faculty of Architecture and City Planning, Kunming University of Science and Technology, Kunming, China \\ Email address: \\ 305629261@qq.com (Gao Jie), 599046919@qq.com (Zhai Hongyu) \\ ${ }^{*}$ Corresponding author \\ To cite this article: \\ Gao Jie, Zhai Hongyu. The Protection and Activation of Shanxi Jinzhong Historical and Cultural City from the Perspective of Humanity. \\ Urban and Regional Planning. Vol. 5, No. 2, 2020, pp. 70-76. doi: 10.11648/j.urp.20200502.15
}

Received: June 1, 2020; Accepted: June 28, 2020; Published: July 132020

\begin{abstract}
China has a large number of traditional dwellings and a wide range, which truly reflects the production and living conditions, religious beliefs and aesthetic concepts of local residents at that time. It can be said that dwelling are living fossils for studying anthropology and architectural history. However, with the rapid development of the economic situation, the protection of traditional dwellings has also been strongly impacted. The protection and activation of the traditional dwellings will become the focus of attention in the future. This paper explores the methods and purposes of the protection and activation of traditional dwellings through an investigation of the ancient city of Pingyao in Jinzhong, with a dynamic and static combination, multicultural coexistence of academic vision. Through the dual exploration of the material cultural heritage and the intangible cultural heritage, we can inherit the characteristics of the traditional folk houses and use the strategy of the traditional block layout for reference, so that the historical cultural heritage which can not be copied and rebuilt can be preserved. It is also the primary goal of contemporary architectural history workers.
\end{abstract}

Keywords: Traditional Dwellings, The Ancient City of Pingyao, Protection, Activation, Multicultural

\section{The Basic Profile of Pingyao Ancient City in Shanxi Province}

The ancient city of Pingyao, located in Pingyao County, south of Jinzhong City, was founded in the Xuanwang period of the Western Zhou Dynasty. It is an outstanding representative of the Chinese culture of the Ming and Qing dynasties.

\subsection{The General Location of Pingyao Ancient City and Its Structure Characteristics}

The ancient city of Pingyao is one of the only two cases in China that successfully declared the world's cultural heritage with the entire old city. Its historical and cultural value, as well as for the traditional dwellings protection and activation of the theoretical reference, its typical demonstration role is self-evident. The ancient city of Pingyao is located on the eastern edge of the Loess Plateau, and it is a square-shaped city and facing the south. According to the topography and sunlight, it is 15.1 degrees east.
One gate were opened on the north and south walls of Pingyao, and two gates were opened on the east and west walls. Because of the advantages of geographical location, agriculture and commerce are very developed in Jinzhong. During the Ming and Qing Dynasties, Jinzhong merchants accumulated a lot of wealth. The houses were large in scale and well decorated. The buildings they lived in all showed their status and wealth. At the same time, it also showed the cultural concept and value orientation of Shanxi merchants. Residents of Jinzhong follow Confucianism, the folk customs are simple, respect for the law, and the architecture also reflects the strict code of etiquette principles. (Figure 1)

\subsection{A Probe Into the Value of Traditional Dwellings in the Ancient City}

\subsubsection{Historical Value}

The historical value of traditional dwellings can only be used, can not be inherited in the new buildings. The reason the conventional houses has some historical significance is that it is the real products of the past era, which objectively records the social, economic, political, and cultural 
conditions of that era. The historical value of traditional dwellings in Pingyao is mainly reflected in the architectural relics of Shanxi courtyard, shared courtyard, temple hall and so on, which are represented by the culture of Shanxi merchants, Ming, Qing, and Han culture, they genuinely reflect the production and living conditions of Pingyao ancient city, the "dry dock" of economic prosperity in the Ming and Qing dynasties, and are "living fossils of our research history.

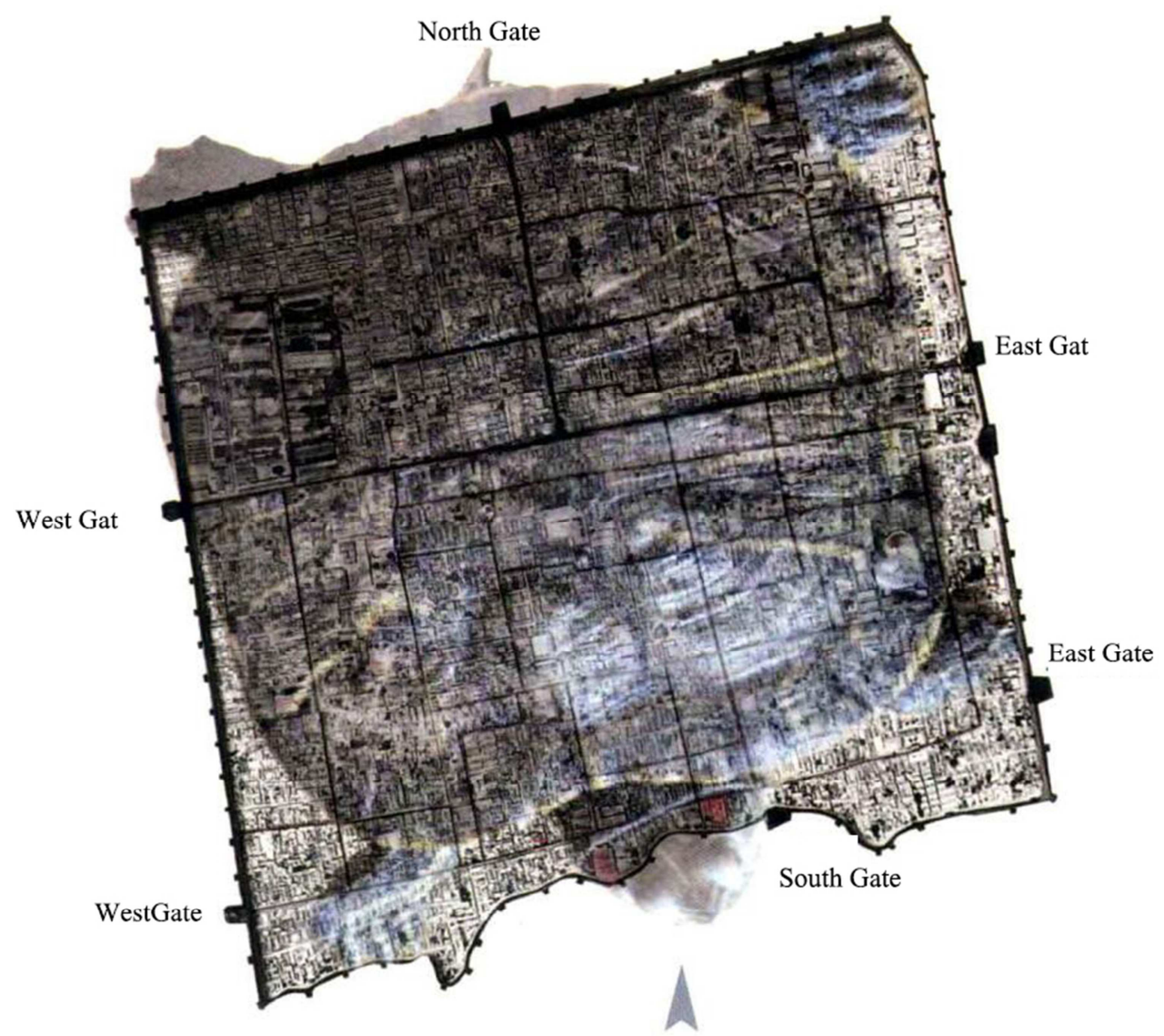

Figure 1. Road Network Diagram of Pingyao Ancient City.

\subsubsection{Cultural Value}

The architectural decoration, religious folklore, and planning layout in the ancient city of Pingyao reflect high cultural value. The city adopts asymmetrical design in the center axis, which is rigorous and regular. According to the principle of the left for the top, right for the bottom, the City God Temple is set to the east of the axis, the county government is placed to the west of the shaft, and the two sides are juxtaposed, the idea of integration of nature and human in the performance here incisively and vividly.
Qingxuguan, the temple of fire and other Taoist buildings is located in the east of the axis, Jifu Temple, Jixiang Temple are located in the west, consistent with the pattern of Taoism on the left and Buddhism on the right. The Confucian Temple is on the Left, Guanyu Temple is on the right. Confucian Temple and Guanyu Temple are ranked respectively. This layout embodies the Confucian maintenance of imperial power under the unified world, the hierarchy of strict order, feudal rule of imperial consciousness, and so on. (Figure 2)
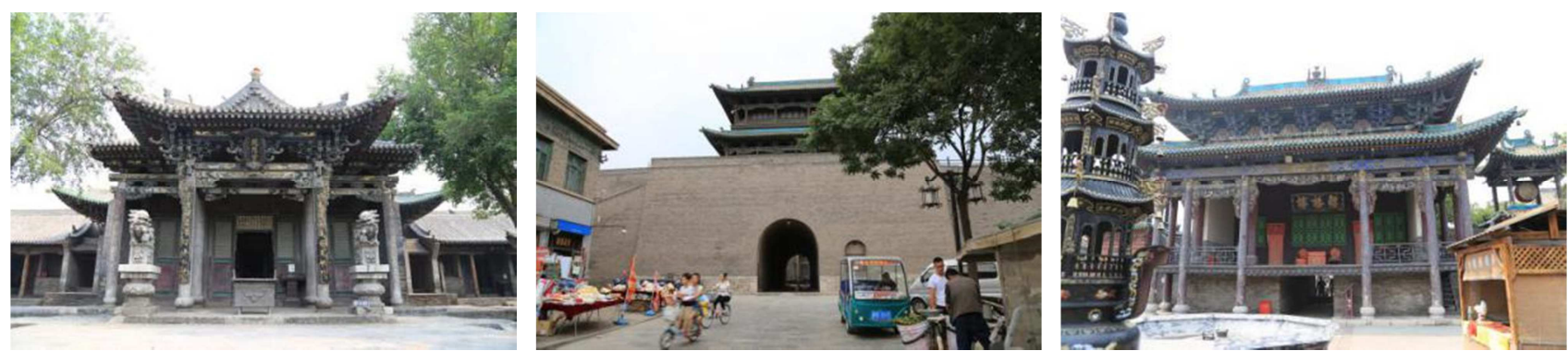

Figure 2. Different types of Public-buildings in Pingyao ancient city (Image Credit: Shoot it by myself). 


\subsubsection{Architectural Creative Value}

In terms of the architectural form, Jin merchants respect Confucianism, the houses they live in are strictly by the ancient rules of etiquette. The courtyard space is square, and the layout is compact, it has the apparent longitudinal axis. The Jinzhong dwellings broke through the traditional one-to-two courtyard and developed into a horizontal and vertical groups. The traditional houses in the ancient city of Pingyao have several types of courtyards one is a three-in courtyard or a four-in courtyard inhabited by ordinary people, one is a small shop along the street, which is used for business, and the other is to do business in a front room like Escort Agency, the houses in the back are for rest, there are kinds of houses, such as the Longitudinal multi-entry courtyard, the horizontal multi-span parallel courtyard, and the horizontal multi-entry multi-span Group courtyard.

Because of the drought and lack of rain in Jinzhong area, the houses are all single-sloped roofs, so that rainwater can flow along the eaves into the narrow courtyard, and the water tanks in the courtyards can be used to prevent fire. Liang Sicheng described Pingyao's architecture as "beautiful on the outside and beautiful on the inside", with tall walls externally and elegant courtyards internally. The atmosphere is completely different from the Beijing courtyard with the atmosphere of open, as it has more Jiangnan style (Figure 4).

As a representative of the culture of Ming, Qing, and Han dynasties, the complete form, architectural form, and sculpture art of the ancient city have high architectural creation value, which is worth studying and inheriting (Figure 5).
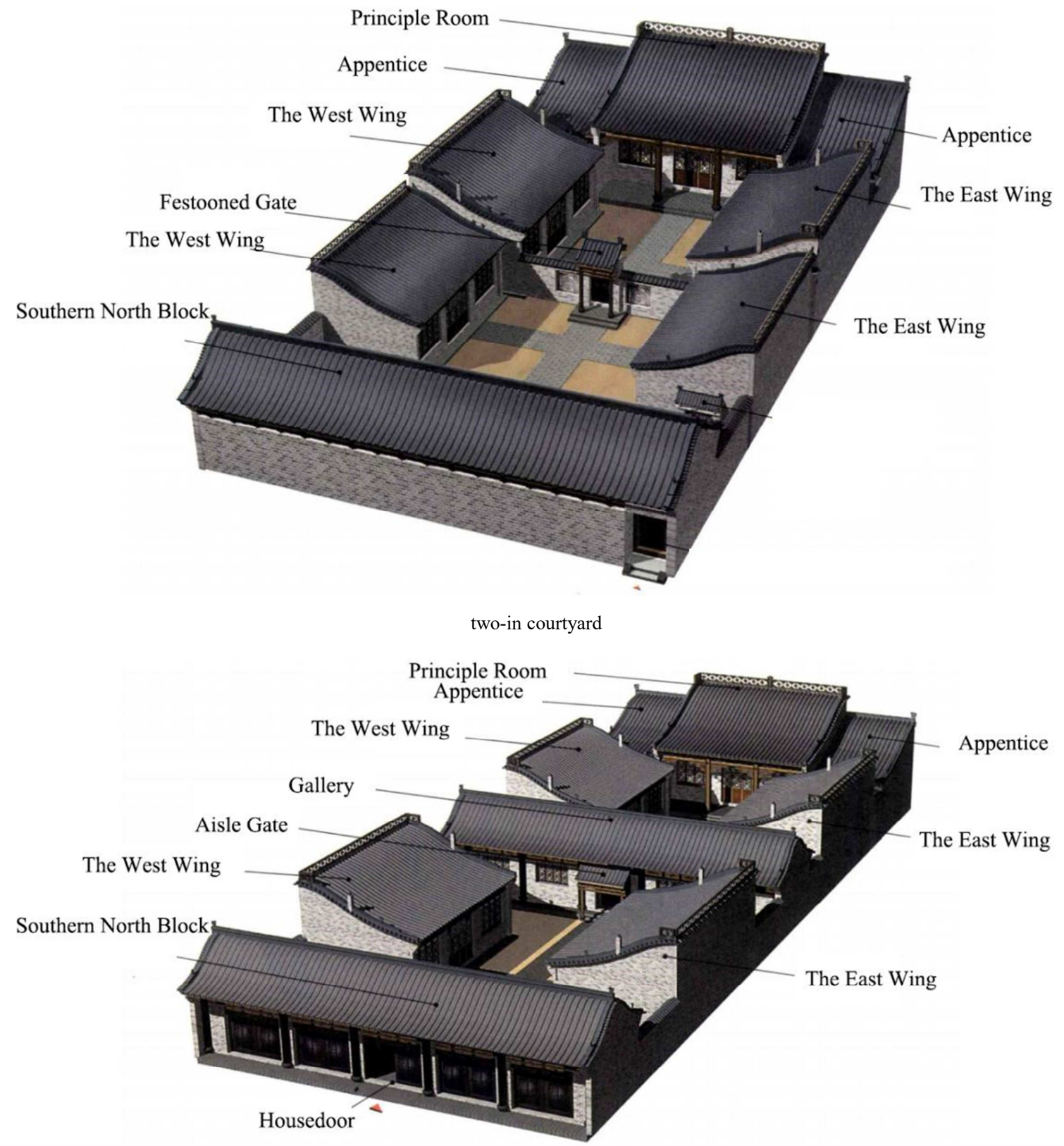

Two into the House through the hall 


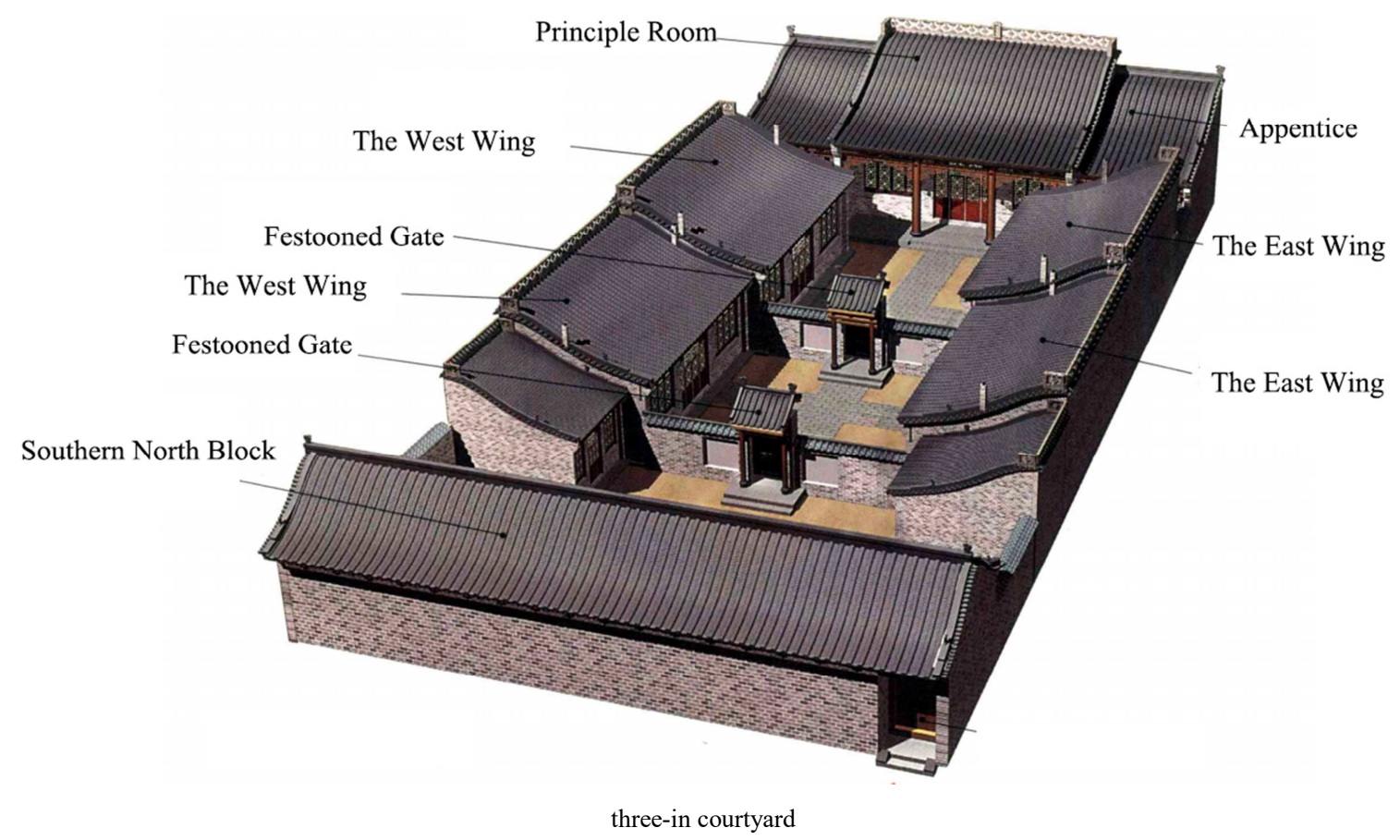

Figure 3. Courtyard of Pingyao traditional dwellings (Image Credit: It says the ancient city of Pingyao).

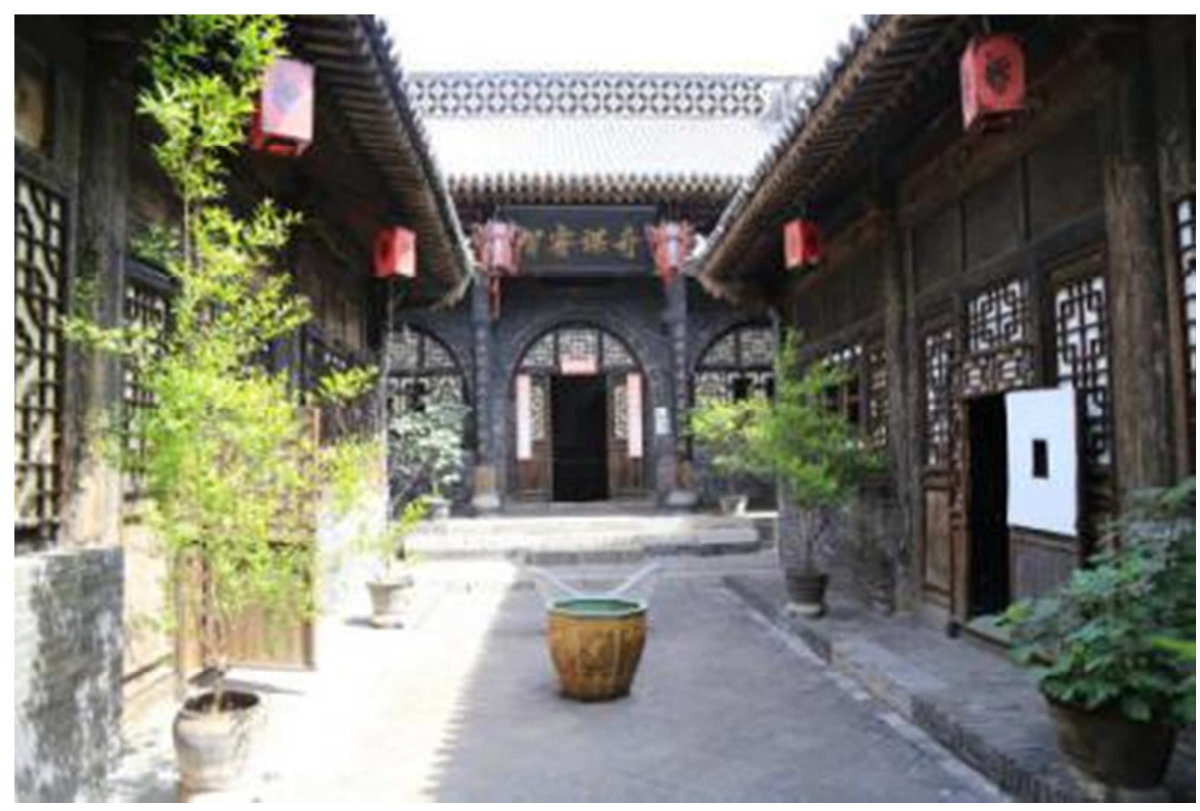

Figure 4. Pingyao Courtyard (Image Credit: Shoot it by myself).
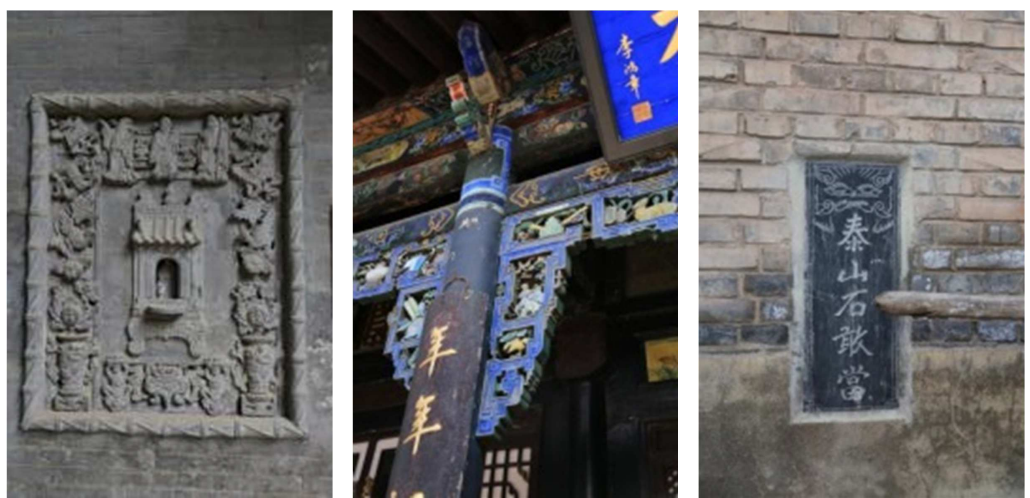

Figure 5. Woodcarving, brick carving, stone carving and murals in the ancient city (Image Credit: Shoot it by myself). 


\section{Protection and Utilization of Traditional Dwellings}

\subsection{In a Crisis}

With the rapid development of the economy and the continuous improvement of people's living standards, traditional cities are also urgently seeking their transformation and renewal. New Buildings are constantly being built in the cities, the transformation of the old city plan is suddenly emerging like a storm, Traditional culture is strongly impacted by modern culture, At the same time, the traditional houses are demolished and destroyed. The cultural characteristics and geomorphological features they represent are also gradually lost. Goethe said that "Architecture is the frozen music", and architecture is the carrier of culture and the imprint of the times. To retain traditional dwellings and properly protect and utilize them is a respect for history and a legacy for the future.

\subsection{Reflection on Two Ways of Protection}

Among the many examples of dwelling protection, there are some ways of protection that are worthy of our learning. However, there are many problems with some protection methods, which deserve our serious reflection and evasion. In the protection of dwellings, how to "correctly treat the protection of the four elements, namely the protection of individual historical buildings, the protection of historical streets and lanes, the protection of the layout of historical building and the protection of the spatial pattern". Trying to avoid over-protection and over-development does require serious thought.

\subsubsection{Overprotection}

Some cultural relics protection units with significant historical value, such as Wang's Grand Courtyard, Escort Agency, have very high values in architectural decoration, spatial layout, and scale, and it is impossible for future generations to live in them, there is nothing wrong with museum-style protection. However, for many ordinary traditional houses, museum-style protection is extremely not feasible, and more effective protection measures should be explored. The architecture has memories, and the ancient villages and ancient towns further reflect the continuation of the local residents' production, life and blood spirit. After thousands of years of inheritance, the residents of the same surname have established themselves here, survived and developed, followed their beliefs and customs, the spirit of their culture. For example, blindly moving out of residents for rigid protection, leaving them away from their homes, ignoring human factors, adopting frozen museum-like protection, the simple security of material space and material industries, it would be foolish to preserve only a lifeless. "The dwellings and their settlements most directly reflect the living conditions of human beings such as food, clothing, and transportation in various historical periods, as well as social conditions such as economic systems, productivity, and production relations."

At any time, the role of "people" is very important. The reason why a region or a building has a soul is that different people give them different lives and meanings, so that they can have a story to tell in the long river of history.

In the ancient city of Pingyao, the residents still live their ordinary and quiet life, still living in the ancient courtyard, morning and evening, the ancient city seems to have only added some traces of the passage of time. Those traditional humanistic imprints are always there. What can we do to keep the local residents in our increasing commercialization and prosperous world, apart from their presidents' attachment to their homeland.

First of all, while protecting the external form and internal structural characteristics of traditional residential buildings, we should fully improve their internal living facilities to ensure the basic life of the people and live more comfortably.

Secondly, to protect the original way of production and life of the residents, in the process of relocation and reconstruction of some buildings, the residents should be resettled to ensure the continuity of their lifestyle and neighborhood relationship.

Third, the development of tourism in the ancient towns, the people can also participate in the tourism industry to mobilize enthusiasm, increase income and create benefits.

\subsubsection{Overdevelopment}

In the old town, the injection of modern factors is inevitable. The traditional residential settlement should be developed, sustainable, and reflect the characteristics of the times. The pure protection is static, and only the dynamic continuity will not interrupt the historical development context. Nowadays, the development of tourism is the most feasible way of protection. However, excessive development and commercialization will inevitably lose the cultural attributes of traditional residential settlement and make people ignore its cultural value, eventually lead to the similarity and loss of characteristics in ancient cities. How should the government make good use of the double-edged sword of tourism development, and keep its originality to a greater extent.

First of all, attach importance to cultural values and consider both the material and non-material protection. Pingyao County is an important town embodying the culture of Jin merchants. Under the brick walls and tiles of the ancient city, it also has very touching stories and legends. Wang Chaoge's "Seeing Pingyao" played on the edge of the ancient town again and again, and constantly telling people a story of the continuation of the blood. Everyone who has seen "Seeing Pingyao" will have a new understanding of the ancient town, not only its unique material entity, but also a very respectful feeling for the people and culture of Pingyao. This way of integrating the stories and legends of the ancient city into the film and television performance can also let people more in-depth understanding of the local culture.

Second, prevent cultural faults and coordinate the traditional and modern development. History is constantly developing, and it should also be true. The modern factor 
cannot be ignored to simply maintain the history, not to put an end to the injection of modern factors. Control the mainline and letting it go is the best solution. For example, in terms of transportation, the ancient city of Pingyao has banned motor vehicles from several main streets for traffic congestion, however, modern vehicles are still allowed on the secondary streets. The entire ancient city is operating normally under normal life. The neon lights flickered at night, and often packed with tourists, but after eleven o'clock, the whole ancient city gradually became quiet and restored to the simple and quiet atmosphere.

At the same time, in terms of inheritance and utilization, we should also attach importance to the innovation, and flexible use of various ways to promote its sustainable development. While protecting the traditional industry, we should attach importance to its development and innovation, so that it can be accepted by most people, passed on by word of mouth, and gradually developed into a characteristic industry of traditional settlement.

\subsection{Restoration}

For the restoration of ancient buildings, we have taken a lot of detours all the time. Some think that the newer the better, the more magnificent the better, the more complete the better, focusing on the appearance instead of the traditional truth. It turns out to be fake and boring. It destroys the purest part of traditional architecture.

For the restoration of traditional architecture, we should try our best to keep the original appearance. During restoration and reconstruction, traditional building materials and technologies should be used as much as possible to show its original essential features.

Most of the traditional dwellings are no longer used for the original functions, for example, the former residence used for the sales of commodities or converted into a museum. This situation is inevitable, in this case, a reversible transformation should be carried out so that it can meet the current use requirements and return to the original appearance, instead of large-scale reconstruction and expansion, eventually, there was no turning back.

Some of the buildings are in important areas, but they are already in ruins and cannot be repaired. They can only be demolished and rebuilt. In this case, there are two methods to adopt. One is to rebuild the project as much as possible to ensure its original appearance and protect the integrity of the block; the other is to build modern buildings that conflict with other buildings to highlight the characteristics of the times. In a word, the authenticity of history is the soul of cultural relics and historic sites. The purpose of protection is to truly and comprehensively preserve and continue its historical information and its full value.

\section{Conclusion}

Through the analysis of the above content, the protection and activation of traditional dwellings should adopt corresponding protection methods according to different characteristics and requirements: the first type is an important historical and cultural relics protection unit, which adopts museum-like system protection, and the dwellings still retain original style and feature. This method of protection is the best for the protection of material heritage with the least damage. One is the ordinary traditional dwellings with a large number of residents to live, which adopts the method of preserving the external form and improving the internal facilities. For the traditional dwellings that have been severely damaged and have to be demolished, the local resettlement method is adopted. In this way, to retain the traditional style, while consciously into contemporary factors. The other is along with the street shop. While encouraging commercial development, avoid losing local characteristics, adopting business in the front and sleep in the back to stimulate the enthusiasm of local residents. Traditional dwellings always have a soul. It carries thousands of years of history and the blood of generations. The bluestone roads, the gray and white walls, and even broken walls we see today have very important historical value, this historical value can not be copied and reconstructed.

Therefore, only the combination of dynamic and static, through the coexistence of multiculturalism, and through the dual protection of human and material factors, the traditional dwellings can be inherited and sustainable development.

\section{References}

[1] Cao Changzhi. The Ancient City of PingYao. In Illustration. Shanxi Economic Publishing House. 2010. 9.

[2] Yang Dayu. Yunnan Dwellings. China Building Industry Press. 2009. 12.

[3] Yang Dayu, Zhu Liangwen. Yunnan Dwellings. China Building Industry Press. 2009. 12.

[4] Wang jinping, Xu Qiang, Han weicheng. Shanxi Dwellings. China Building Industry Press. 2009. 12.

[5] Amos Rapoport, House form and culture. China Architecture \& Building Press, 2007.

[6] Amos Rapoport, The Meaning of the Built Environment: A Nonverbal Communication Approach, China Architecture \& Building Press, 1992.

[7] Bernard Rudofsky, Architecture Without Architects-A Short Introduction to Non-Pedigreed Architecture, University of New Mexico Press, 1987.

[8] Cui yangbo, Research on the Construction of the Neo-vernacular Architecture from the Tectonic View, Xi An University of Architecture And Technology, 201.

[9] Lindsay Asquith, Marcel Vellinga. Vernacular Architecture in the 21st Century: Theory, Education and Practice. London: Taylor \& Francis, 2006.

[10] Paul Oliver. Dwelling--The House across the World. Oxford: Phaidon Phaidon Press Ltd, 1987.

[11] Paul Oliver. Encyclopedia of Vernacular Architecture of the World. Cambridge University Press, 1997. 
[12] Paul Oliver. Dwelling: The Vernacular House World Wide. Oxford: Phaidon press Ltd, 2003.

[13] Bernard Rudofsky. Architecture without architects. New York: Doubleday \& Company lnc, 1964.

[14] Tracy Miller. Dayunyuan before Dayunyuan: the Design of
Xianyanyuan's Amitabha Hall. Senior Academics Forum on Traditional Chinese Architectural History. Nashville: Vanderbilt University, July 23-25, 2015.

[15] Henry Glassie. The Vernacular Architecture. Indianapolis: The Indiana University Press, 1999. 